\title{
EVALUATION OF HPGR AND VRM FOR DRY COMMINUTION OF MINERAL ORES
}

\author{
A. Jankovic ${ }^{1, \#}$, C. Ozer ${ }^{2}$, W. Valery ${ }^{3}$, K. Duffy ${ }^{1}$ \\ ${ }^{1}$ Metso Process Technology and Innovation, PO Box 221, Kenmore, QLD $406^{\circ}$ - ctralia \\ ${ }^{2}$ Metso Process Technology and Innovation, P.O. Box 306, FI-33101, Tan cre, Fin d d \\ ${ }^{3}$ University of Queensland, St Lucia QLD 4072, Australia \\ (Received: February 2, 2016; Accepted: November 4

\begin{abstract}
The mining industry is searching for more energy efficient and dry conventional crushing followed by wet grinding circuits. This is a res increasing energy cost, scarcity of water resources and stricter environme legislation. Dry comminution technologies, such as High Pressure Grinding Rolls (HPGR) and Valler Min VRM), have been successfully used in other industries such as cement and coal for decades, ad the literature clatw, that these technologies are more energy efficient than conventional comminution practic Pilot scale sting was conducted for each of these technologies using rock with properties similar to many mine ores to test claims in the literature and evaluate the applicability for hard rock mining operations. Whilst the results fo he HPGR and VRM are not directly comparable (due to different degree of size reduc a), both a vistrat the potential for considerable energy savings compared to conventional ball milling. The and air ctons lcation circuit used $20-30 \%$ less energy than the HGPR, screen, ball mill circuit. While VRM as es a to use 10 - $30 \%$ less energy (depending on the type of VRM) than a ball mill circuit for a similar degr of omminuiton.
\end{abstract}

Key words: comminution; HPGR RM; en gy effic acy; air classification; ball mill.

\section{Introduction}

Traditionally, th con inution of dineral ores involves y crushin of moist ore followed by at grinding an classification stages to $\mathrm{r}$ ch a to set grind size. However, the mining in stry ig facing growing chall or asso ted $y$ the increasing cost of chergy scarch of water resources in s. ne lo ato and tighter environmental leg. on. Consequently, the mining industry is sear ing for more energy efficient and dry comminu, on equipment as an alternative to conventional crushing and wet grinding circuits. Dry comminution technologies, such as High Pressure Grinding Rolls (HPGR) and Vertical Roller Mills (VRM) have been successfully used in other industries for decades. However, there are only a few examples of these technologies in mineral ore applications to date.

HPGR in closed circuit with air classification have been used in the cement industry since 1985 for reliable pre-mill or final product grind, reducing power and steel usage cost, and increasing capacity, while generating high quality product as fine as 25 $\mu \mathrm{m}[1,2]$. In recent times, studies and applications of HPGR for mineral ores have become more common. Several notable hard rock installations include Cerro Verde McMoRan Copper-Molybdenum in Peru, Mogalakwena Anglo American Platinum in South Africa, Boddington Newmont Copper-

${ }^{\#}$ Corresponding author: alex.jankovic@metso.com 
Gold in Australia, Grasberg McMoRan Copper-Gold in Indonesia, CVRD Iron Ore in Brazil, Kudremukh Iron Ore in India, El Brocal Lead-Zinc and Copper in Peru, CAP Minería Iron Ore in Chile, and SNIM Iron Ore in Mauritania [3-5].

The current VRM design has been available since the early 1900s, and is accepted technology in the cement, power and industrial minerals industries. VRMs are recognised as one of the more efficient comminution devices currently available and are used today to simultaneously grind and dry materials such as limestone, quick lime, cement raw materials, talc, bauxite, magnesite, phosphate, feldspar, barites, graphite and coal [6]. The dominant use of the VRM is in raw material for cement production and coal grinding, but there are very few examples of VRM usage within the broader mining industry: Schaefer [7] describes VRM grinding of phosphate, while Geroldet al. [8] report applications in copper matte, steel slag and tin slag grinding.

There is a growing interest in both HPC and VRM for application to miner-res du to the claimed benefits in energy efficiency as well as the fact that they are dry processes. They can also achieve a large reduction ratio (from about $-40 \mathrm{~mm}$ down to about $50 \mu \mathrm{m}$ ) in a single process step. To test these claims from the literature, pilot scale testing has been conducted of both these technologies treating a rock with properties comparable to that of many mineral ores; a basalt rock obtained from a local quarry. In each se the ergy efficiency was evaluated an ompared in $\mathrm{h}$ a conventional ball mill fo the inding of his relatively hard rock.

\section{Description or he chnology}

HPGR VRM tech o are similar in the fau that main breakage mechanism of bothic compress n breakage, they are both $\mathrm{dr}$ processes, and they are applicable across a $\mathrm{s}$ filar size nge. However, the machines th nselves ar very different and the HPGR ope tes at nificantly higher pressures than VRM. Two technologies are illustrated in

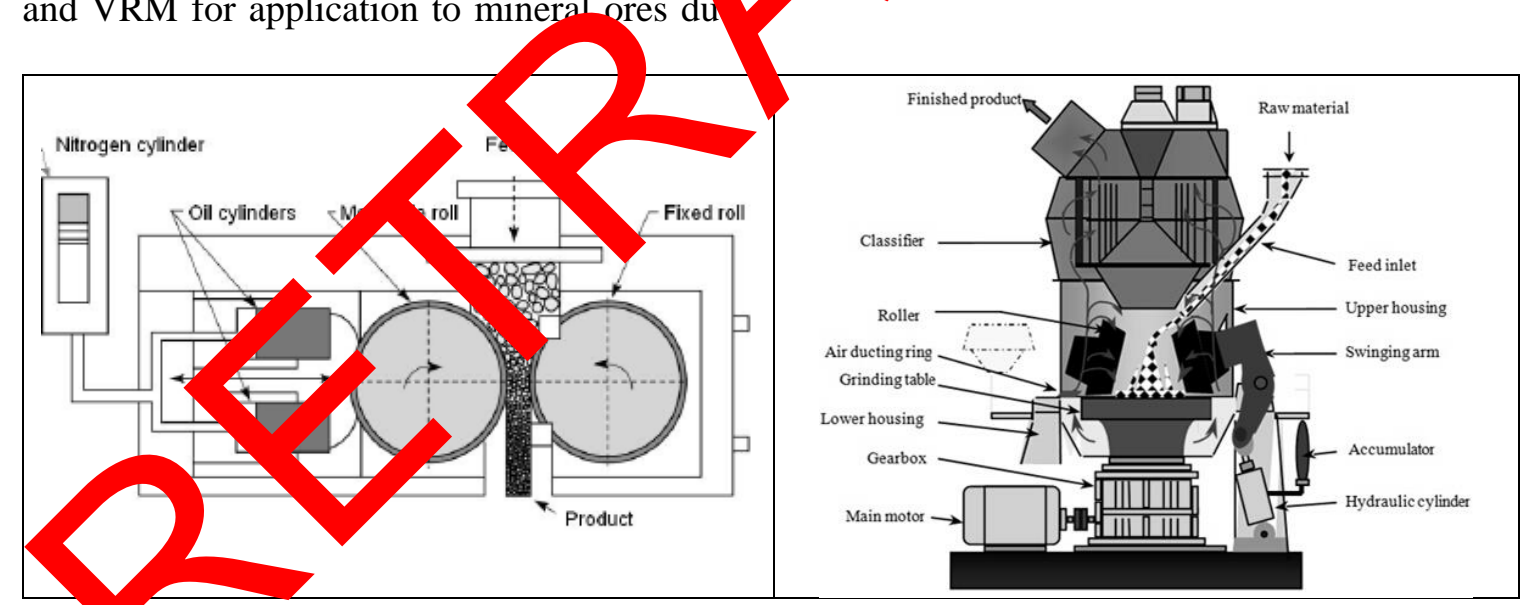

Figure 1. (a)Schematic of HPGR and (b)Schematic of air-swept VRM

The HPGR comprises two motor driven counter rotating rolls, one fixed, and one acting against hydraulic cylinders connected to pressurised nitrogen accumulators. Rock is choke-fed to the roll gap, with nip and pre- breakage occurring for particles larger than the gap by single particle comminution, and smaller particles forming a compressed bed between the rolls enabling more efficient bed breakage mechanics [3]. 
One of the main benefits of HPGR use is comminution energy efficiency, with researchers reporting energy savings of about $10-50 \%$ compared to grinding by conventional ball and rod milling or semiautogenous grinding with ball milling [3, 9, 10].The reported energy savings depend on the circuit arrangements, whether the grinding is being carried out wet or dry, the hardness of the ore, the amount of additional material handling operations and the methods used to define the energy savings. Other benefits include reduced water and grinding media use, further reducing operational costs [3].

In a VRM, material is fed to the grinding table where it flows outward under the influence of centrifugal force and is ground between the grinding elements (rollers and grinding table). They are available as two types; air-swept and overflow. In air-swept VRM the classification is fully internal, with the fines and middlings transported pneumatically from the grinding chamber to the dynamic, high efficiency vane classifier at the top of the VRM. In overfle VRM designs, material fed onto th rindin. table is allowed to overf $\rightarrow$ in the recirculating stream from which is mechanically transported 0 a e crnal a. classifier. In this mode the requh d duty of the fan is appro in $y$ halvea, which considerably reduces th total energy requirement of he circuit. Fo [11] reports a $41 \%$ crease in specific energy consumptio in pilot scale testing of magnem in 1970 aue to external recirc ation and o cation. Ito et al. [12] f nd tha Kawasaki CKP overflow VRM is av $1 \%$ me efficient than conventional VRM in pilot-scale finish grinding of cement.

There have been several recent studies of the energy efficiency of VRMs. Pilot scale results by Altunet al. [13] indicate a potential decrease of $18 \%$ in energy consumption using a VRM compared to an existing rod mill/ball mill circuit when processing copper ore. Ito et al. [12] report that at industrial scale, the roller mill consumes at least $20 \%$ less specific energy compared to the roll press \& tube mill or only tube mill circuits operating in the same plant. Based on pilot tests and simulations, van Drunicket al. [14] confirm the energy efficiency of VRMs trooting zinc ore in comparison with other cuit tions, especially in overflow mode

The benefits of VRMs in proces ng circuits appear not to limited imp ved energy consumptio but als better ciency in downstream apeh ion crosbie et al. [15] reported enb aced ation atics and grade-reco curves fo, $P, M$ and copper ores. Th VRM vroducts had narrower size distributions cons red to the products pr ared by convent, nal comminution. The $\checkmark$ M produc also showed improved mineral li ration an increased deportment of val. ble $m$ erals to size classes that responum oetter to flotation.

\section{HPGR Experimental}

Two HPGR flow sheet options were tested. Option A comprised a HPGR closed with an air classifier generating final product directly from $-10 \mathrm{~mm}$ feed. Option B comprised the same HPGR closed with a $2.36 \mathrm{~mm}$ screen, producing feed for a Bond mill test closed with a $75 \mu \mathrm{m}$ screen to generate the final product. The power consumptions of the HPGR, Bond mill and air classifier were directly measured and recorded via inline power meters, while the power consumption of the Bond mill and a scaled-up mill were also calculated using various methods for comparison. Additional Bond index tests were conducted on standard $-3.35 \mathrm{~mm}$ Bond test feed, $-2.36 \mathrm{~mm}$ crushed feed, and HPGR crushed $-2.36 \mathrm{~mm}$ feed to aid in energy comparison analysis. 
The test material used in both the HPGR and VRM pilot scale testing was basalt rock obtained from a local quarry. Bond work index testing conducted in these test programs confirmed the sample was relatively hard and comparable to many mineral ores.

The sample was pre-screened using a "Russel" vibrating sieve with a $10 \mathrm{~mm}$ aperture size, and the oversize was stagecrushed using a laboratory jaw crusher to pass $10 \mathrm{~mm}$. The resulting $-10 \mathrm{~mm}$ sample was homogenised and split into 32 portions of 15 $\mathrm{kg}$ using a 16-bin rotary splitter. A representative sub-split was taken for size analysis using a 12-bin rotary splitter, and a further sub-split was taken using an eight-jar rotary splitter to achieve a $500 \mathrm{~g}$ sample for size analysis. The P80 of the $-10 \mathrm{~mm}$ aggregate feed was $7.4 \mathrm{~mm}$. The feed for the Bond tests was prepared by stage crushing $30 \mathrm{~kg}$ of the $-10 \mathrm{~mm}$ sample to pass $3.35 \mathrm{~mm}$.
Half of the $-3.35 \mathrm{~mm}$ material was split out and retained for the $3.35 \mathrm{~mm}$ Bond tests, while the other half was screened at $2.36 \mathrm{~mm}$ to produce the sample for the $2.36 \mathrm{~mm}$ Bond tests.

A KHD rotating wheel air classifier and a fully instrumented Krupp Polysius HPGR unit was utilised in this test work. These are shown in Figure 2.The energy concumption of the classifier was logged usi o a $N$ oVip Plus digital clamp-on power eter, conn ted via a serial interface to a running he associated logging atware. no bad consumption was detern ted the average instantaneo pe er dray of the fan motor prior t and afu sample ceding. The classificati ower dra oad power draw) is ne po r draw during feeding, and the notmower dra is the difference between lo and no-load draw.

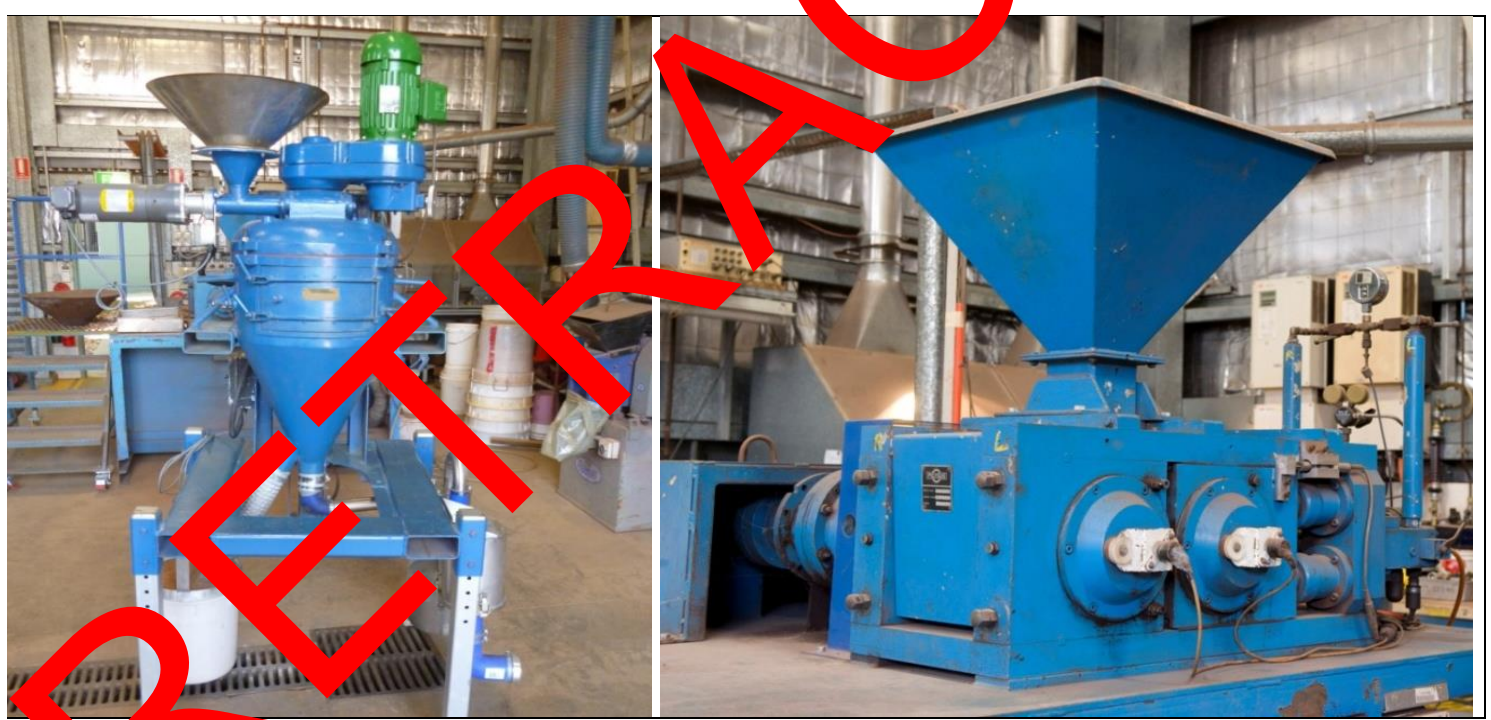

Fitgure 2. (a) Air classifier and (b) HPGR equipment. Photos: CSIRO

The p ver consumption, working pressure and operating gap of the HPGR were logged by a computer with Labview software, and a standard peripheral roll speed of $0.38 \mathrm{~m} / \mathrm{s}$ was used in all tests. The oil pressure was set at
4.5 Mpa and the gas pressure was set at 1.5 $\mathrm{MPa}$ to give an oil and gas pressure ratio of $3: 1$, while a nominal roll gap of $1.6 \mathrm{~mm}$ was used, which achieved the desired specific press force of about $4-5 \mathrm{~N} / \mathrm{mm}^{2}$. Size analysis 
was carried out on all feed and product samples by splitting to $300 \mathrm{~g}$ and wet screening over a $38 \mu \mathrm{m}$ screen, with the oversize being dry screened using a standard screen series from $9500 \mu \mathrm{m}$ to $38 \mu \mathrm{m}$.

\section{Test Procedure}

\section{Option A - HPGR in closed circuit with air classifier:}

For each grinding cycle, $20 \mathrm{~kg}$ of sample was passed through the HPGR followed by air classification. Fresh feed equivalent to the quantity of removed fine product was added to the coarse product of the air classifier, homogenised by three passes through a 12-bin rotary splitter, and utilised as feed for the next cycle. Six locked cycles were completed at the determined press force, with feed and product samples taken for size analysis.

\section{Option B - HPGR in closed circuit $y^{\text {vith }}$ $2.36 \mathrm{~mm}$ screen plus ball milling:}

For each grinding cycle, $30 \mathrm{~kg}$ of ple wa passed through the HPGR foy wed y dry screening at $2.36 \mathrm{~mm}$. Feed the ne ve was produced by adding $f / \mathrm{sh} / \mathrm{d}$ quivale to the amount of remoy screen dersize to the screen oy ots follow by homogenising by three pas s through a 12 bin rotary $\mathrm{sp}^{1}$ er. Six lock cycles were performed, with $\mathrm{a}^{\mathrm{n}}-2.36 \mathrm{~mm}$ products combined, h nog ased and split to produce a $10 \mathrm{~kg}$ mple $-2.36 \mathrm{~m}$ for Bond testing and ize a lysis.

\section{all all gra ability tests:}

Bond ball mill locked cycle tests were carried out at a closing screen size of $75 \mu \mathrm{m}$ using a standard (305 $\mathrm{mm}$ diameter) laboratory-scale Bond mill with a standard Bond ball charge. Mill energy consumption was logged to computer using the NanoVip clamp-on power meter described earlier. Noload power draw was determined by running the mill empty for 1 hour while logging and then averaging the instantaneous power recorded in the 5 minutes prior to the test. The power draw of the loaded mill was determined by averaging the power draw recorded during testing, with the net power draw being the difference between the load and no-load power draw.

\section{HPGR Results}

For Option A ( $\forall$ GR in $\partial$ sed c. at with air classifier) the a consumption as $6.1-2 \mathrm{~kW} /$ for the air classifier, $7,1.0 \mathrm{kWh} / \mathrm{c}$, he HPGR, and $14.0 \pm 2.2 \mathrm{kWh}$ verall. The circulating load of th-last two cles was approximately 7010 and produced product with a P80 of $5 \mu \mathrm{m}$. A roximately $5 \%$ flake was ge erated by e HPGR; however, it was of low ompete cy, decomposing when fed to classificaron.

air classifier partition curve for the Option A test is shown in Figure 3.The partition curve has not been corrected for bypass of fines to the coarse fraction. The imperfection I, i.e. separation efficiency of the air classifier, was calculated to be 0.29 using Equation 1:

$I=\frac{d_{75}-d_{25}}{2 d_{50}}$

where $d_{25}, d_{50}$ and $d_{75}$ are the particle sizes that have a $25 \%, 50 \%$ and $75 \%$ chance of reporting to the undersize fraction, respectively. In the Option A test, the values of $\mathrm{d} 25, \mathrm{~d} 50$ and $\mathrm{d} 75$ were determined to be 34 $\mu \mathrm{m}, 49 \mu \mathrm{m}$ and $62 \mu \mathrm{m}$, respectively.

For comparison, the imperfection of hydrocyclones ranges from about 0.2 to 0.6 with an average of about 0.3 [16], so the separation efficiency of the air classifier in the Option A test was similar to that of an average hydrocyclone. 


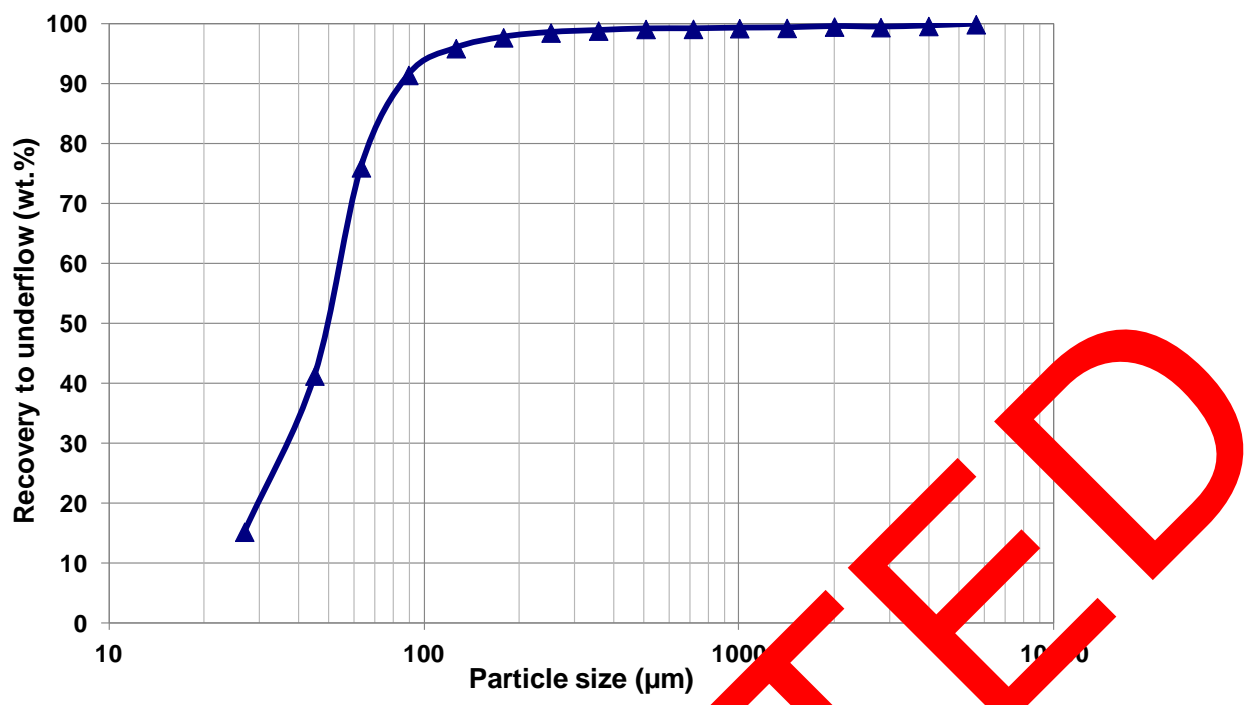

Figure 3. Air classifier partition/efficiency curve from the PGR Option A test.

For Option B (locked cycle HPGR closed with a $2.36 \mathrm{~mm}$ screen and Bond test closed with a $75 \mu \mathrm{m}$ screen), the average net specific energy consumption for the circuit $2.8 \pm 0.4 \mathrm{kWh} / \mathrm{t}$ for the HPGR, $17.1 \pm 1.8 \mathrm{~kW}$ 》 for the ball mill, and $19.9 \pm 2.3 \mathrm{kWh} / \mathrm{t}$ overa The circulating load for the last HPG cycles was approximately $150 \%$

Approximately 5\% flake was generated by HPGR, b it was of low competency and de omposed hen fed to classification. The fina roduc rom the Bond test had a P80 of $7 \mu \mathrm{m}$. Comparative particle size distributions 1 tion $\mathrm{A}$ and $\mathrm{B}$ products and fresh feed are shown in Figure 4.

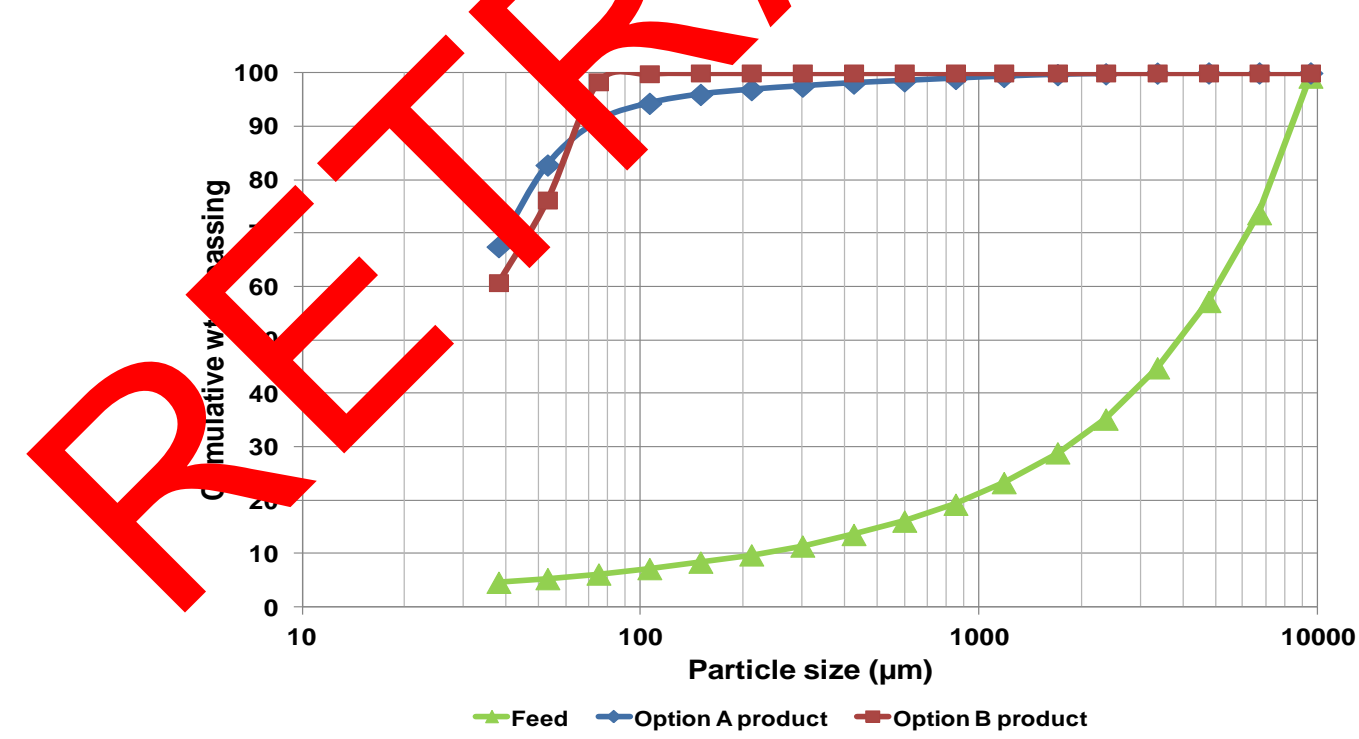

Figure 4. Option A and B final product and fresh feed comparative particle size distributions 
As can be seen in Figure 4, the air classified fine product from Option A exhibits a very wide size distribution; i.e., it contains an unexpectedly large portion of coarse particles $(2.5 \%$ of $0.3-3.0 \mathrm{~mm})$. Considering the P80 of the fine product is approximately $50 \mu \mathrm{m}$, the presence of coarse particles is of concern and an indication of coarse "by-pass" to fines, which may create potential downstream processing problems. Further investigation is required to confirm if this result is common for all similar air classifiers or only for the particular unit and operating conditions tested.

In addition to the Bond test described for Option B above, which used $-2.36 \mathrm{~mm}$ HPGR-crushed feed, Bond tests were also completed using $3.35 \mathrm{~mm}$ standard Bond test feed and $-2.36 \mathrm{~mm}$ jaw crushed feed, all closed at $75 \mu \mathrm{m}$ to produce a similar product to that of Option A $(\mathrm{P} 80=50 \mu \mathrm{m})$ for comparison. It should be noted that the product P80 of these tests $(57 \mu \mathrm{m})$ is larger than, but similar to, that of Option A $(50 \mu \mathrm{m})$. These tests showed that the work indices of standard crushed $-3.35 \mathrm{~mm}$ and $-2.36 \mathrm{~mm}$ feed were similar $(15.0$ and $15.3 \mathrm{kWh} / \mathrm{t}$, respectively) while the HPGR crushed $-2.36 \mathrm{~mm}$ feed produced a lower work index of $14.0 \mathrm{kWh} / \mathrm{t}$. This result mees with observations by Daniel [9] tha APGR - ders a sample more amenable to omminutio by introducing micro-cracks

The aim of thi test wo w to investigate the co sparatiy energ ase of HPGR with air las "ica on and HPGR with screening ap subsed nt bo milling to produce a a ively fine act from a 10 $\mathrm{mm}$ top size h aggregate material. The over "circuit eे rgy consumptions are su marised in Table .

Table 1. Overall circuit option specific energy inpu omparisor esults.

\begin{tabular}{|l|c|c|c|l|}
\hline Stage & Option & Units & Method \\
\hline HPGR from $10 \mathrm{~mm}$ to $50 \mu \mathrm{m}$ & & & $\mathrm{kWh} / \mathrm{t}$ & Direct power \\
\hline Air classifier & & 2.9 & $\mathrm{kWh} / \mathrm{t}$ & Direct power \\
\hline HPGR from $10 \mathrm{~mm}$ to $2.36 \mathrm{~mm}$ & & $\mathrm{kWh} / \mathrm{t}$ & Direct power \\
\hline Ball mill from $2.36 \mathrm{~mm}$ to 57 & 14.9 & $\mathrm{kWh} / \mathrm{t}$ & Bond's third \\
\hline Ball mill from $2.36 \mathrm{~mm}$ to 57 & 19.9 & 17.7 & $\mathrm{kWh} / \mathrm{t}$ & \\
\hline OVERALL & & & \\
\hline
\end{tabular}

The specific energy inp of the Option A circuit (HPGP with air cla fication) was $14.0 \mathrm{kWh} / \mathrm{t}$ ong dir $\mathrm{ct}$ power logging, while it was 19.9 $\mathrm{Wh}$ for the Option B circuit (HPGP with so ening a ball milling) using dire pon $r$ loge $o$ hat is, the Option A cuit cor $29.0 \%$ less energy per tonne of vre proce d than the Option B circu when compared at laboratory-scale. Alternat ly, the specific energy input of the Option B circuit was $17.7 \mathrm{kWh} / \mathrm{t}$ when the ball mill specific grinding energy was calculated using Bond's third law. That is, the Option A circuit consumes $20.8 \%$ less energy per tonne of ore processed than the Option B circuit when the ball mill in the latter circuit is scaled up to a $2.44 \mathrm{~m}$ industrial wet mill. This second comparison, however, does not take into account any potential efficiency increase with up-scale of HPGR and air classifier equipment. The calculation of specific energy input for these tests is described in more detail by Jankovic et al. [17]. The calculated energy savings of Option A are considered conservative because the P80of the product was $50 \mu \mathrm{m}$ while that of Option B was $57 \mu \mathrm{m}$. On the other hand, this study has not taken into account the power consumption of 
ancillary material handling equipment that would be required in industrial scale circuits, or the capital cost of equipment and grinding media. These findings are in line with other published results $[1,2]$.

\section{VRM Experimental}

The VRM tests were conducted using the same basalt rock as used in the HPGR test program. A total of about six tonnes of rock sample, having a top size of approximately 35 $\mathrm{mm}$, was split in to thirty-two samples using a rotary splitter. The sub-samples were crushed using a jaw crusher with a $10 \mathrm{~mm}$ open-side setting to suit the feed size requirements of the pilot-scale VRM.A sub-sample was further crushed to $100 \%$ minus $3.35 \mathrm{~mm}$ and the Bond ball mill grindability index was determined following the standard procedure. The closing screen size was selected as 212 $\mu \mathrm{m}$ for the targeted $\mathrm{P}_{80}$ of around 150-160 $\mu \mathrm{m}$. The Bond work index for the basalt rack used as the VRM feed was found to $15.5 \mathrm{kWh} / \mathrm{t}$. This classifies it as relatively ho rock and aligns well with the index results from the HPGR est $p$ gram (15.0 and $15.3 \mathrm{kWh} / \mathrm{t})$.

The VRM tests were arro o using Raymond Model RP1 $X$ bowl ill at the ALS Coal Division at atory in isbane, Australia. The Raymond ill comprises a rotating table (l $\mathrm{wl}$ ) driven by vertical shaft, three grindi roller $>$ and an integral double cone classin (se rgure 5).

Theramplo as fed the centre of the tab at a te con oll a by a belt feeder. The 1 oper nder negative air pressure and material flowing over the side of the table was pneumatically transported to the internal classifier. Material that was insufficiently fine to be picked up by the air flow dropped into the rejects bin at the base of the mill.

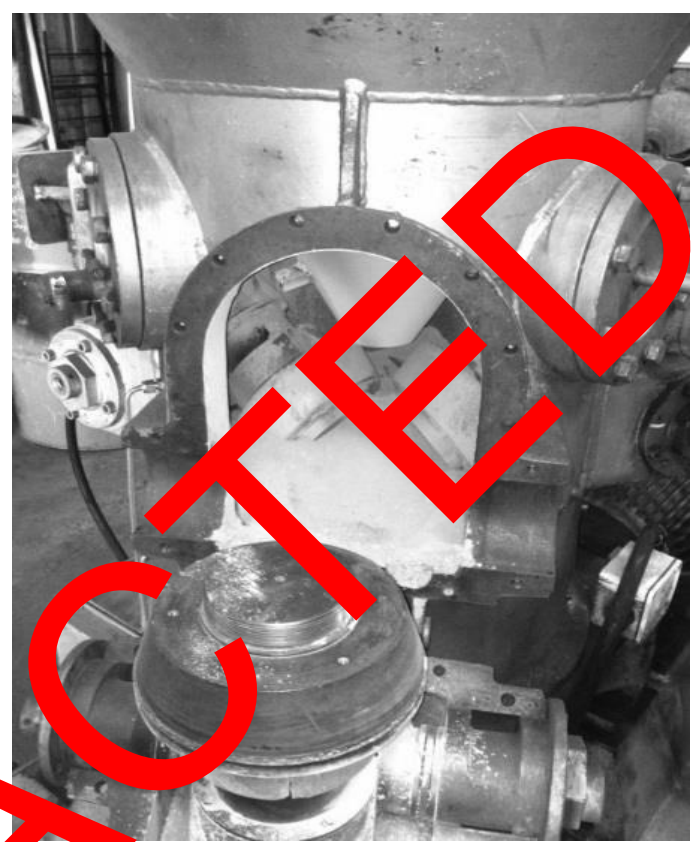

Figure 5. Raymond Model RP153X VRM test unit used for test work

At the classifier, fine particles were transported out of the mill and collected in a bag filter; coarse particles gravitated back to the table. The mill outlet temperature (and thus the mill inlet temperature) was automatically controlled by regulating the natural gas flow to the air heater. Four tests were conducted with operational variable settings as shown in Table 2.

Table 2. Operational variable settings for the VRM tests

\begin{tabular}{|l|c|c|c|c|}
\hline & \multicolumn{4}{|c|}{ Test } \\
\hline Feed rate, $\mathrm{kg} / \mathrm{h}$ & $\mathbf{1}$ & $\mathbf{2}$ & $\mathbf{3}$ & $\mathbf{4}$ \\
\hline Air flow rate, $\mathrm{L} / \mathrm{s}$ & 350 & 850 & 600 & 600 \\
\hline Roller pressure, $\mathrm{MPa}$ & 3.5 & 350 & 280 & 240 \\
\hline
\end{tabular}


The duration of each test was approximately 30 minutes. A sub-sample of $100 \mathrm{~g}$ was split from the product of each test for particle size analysis, by initial wet sieving at $38 \mu \mathrm{m}$ followed by dry sieving of the oversize.

\section{VRM Results}

The particle size distributions of the feed and the products from each VRM test are shown in Figure 6, together with the feed and product size distributions of the standard Bond ball mill tests. The F80 of the VRM feed and the Bond test feed were 13.7 and 2.4 $\mathrm{mm}$, respectively. The P80 from the Bond test was $151 \mu \mathrm{m}$, similar to the P80of the products from the VRM tests, which varied from 155 to $168 \mu \mathrm{m}$. However, the size distributions of the VRM products were wider than the Bond ball mill test product. This may appear to be in conflict with the narrower VRM product size distributions compared to ball mill circuit product reported by Crosbie et al. [15]. However, the classification efficiency for the Bond test is close to $100 \%$ which the fines in the produ At vwer classification efficiencies th mount of hes increases [18] and there gre th product ze distributions from in astrial and ilot cale ball mill circuits b mor fines a w wider size distributic a up ed to Bond test products.

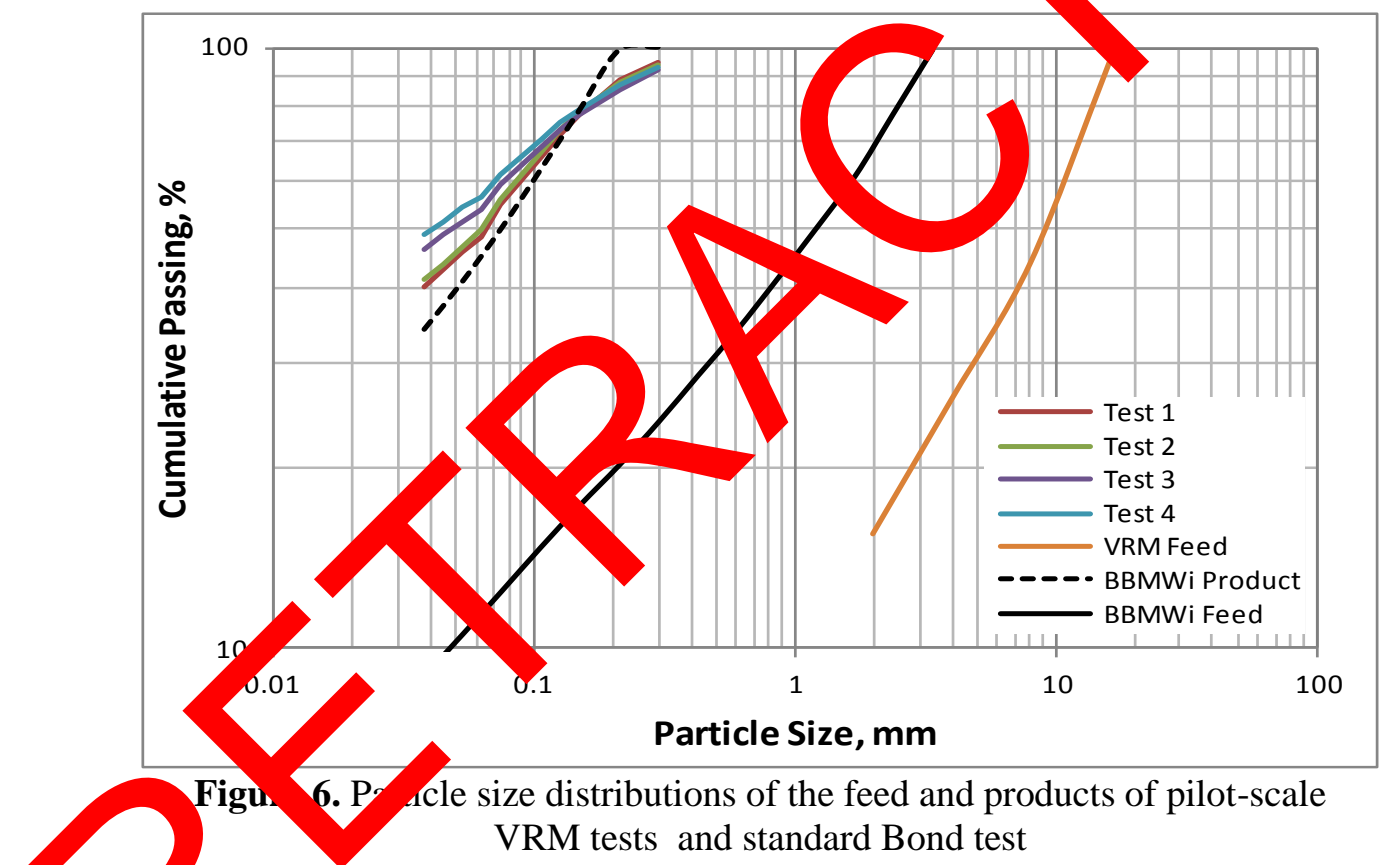

1 variables logged during the tests were mill h tor power draw, air flow rate, differentia air pressure across the table and across the entire mill, roller lift, and mill inlet and outlet air temperatures (see Table 3 ). The no-load power draw of the mill motor was

approximately $0.8 \mathrm{~kW}$. After the completion of each test the wear rate of one of the rollers, the mass of rock left on the table and the amount of material that reported to the coarse rejects bin were recorded (also included in Table 3). 
Table 3. VRM test operating variables

\begin{tabular}{|l|c|c|c|c|}
\hline Variable & \multicolumn{4}{|c|}{ Test } \\
\hline & $\mathbf{1}$ & $\mathbf{2}$ & $\mathbf{3}$ & $\mathbf{4}$ \\
\hline Grinding table motor power, $\mathrm{kW}$ & 5.6 & 6.6 & 6.2 & 6.3 \\
\hline Air flow rate, $\mathrm{L} / \mathrm{s}$ & 348 & 348 & 281 & 240 \\
\hline Roller pressure, $\mathrm{MPa}$ & 3.4 & 6.0 & 6.0 & 6.1 \\
\hline Table differential pressure, $\mathrm{kPa}$ & 1.0 & 0.8 & 0.8 & 0.6 \\
\hline Mill differential pressure, $\mathrm{kPa}$ & 2. & 2.2 & 1.8 & 1.5 \\
\hline Roller lift, mm & 8.8 & 3.3 & 6 & 6.5 \\
\hline Inlet temperature, ${ }^{\circ} \mathrm{C}$ & 160 & 171 & 139 & 48 \\
\hline Outlet temperature, ${ }^{\circ} \mathrm{C}$ & 76 & 76 & 72 & 73 \\
\hline Rollerwear, g/t & 20.4 & 24 & 28 & 2 \\
\hline Mass left, kg & 10 & 7.5 & .3 & 4.0 \\
\hline Rejects (\% of feed) & 0.01 & 0.002 & 0.007 & 0.02 \\
\hline
\end{tabular}

Pneumatic transportation of the grinding table product to the classifier in air swept VRMs is achieved with the pressurised air supplied by a fan. The proportion of fan motor specific energy consumption to the total of fan and the mill motors of VRMs varies considerably in the literature, from 18 to $61 \%$, with most falling between 40 and $50 \%$ [1 19-21].

The power draw of the VRM mill mot was continuously logged durive tes however the pilot scale instrumented to measure the draw. Fan motor power Equation 2 [22]. The $p$ different pressure was measure but the iffere al pressures across the ar mper and filter had to be estimated in oro to determine the overall diff l pressuro The fan motor efficiency $\mathrm{w}$ assumed to be $60 \%$. The measured flow $r$ es were cor cted using the air temperatures co esponding o each section.<smiles>[Te][Te][Te]</smiles>

Where $\mathrm{P}$ is the fan power $(\mathrm{kW}), \mathrm{Q}$ the flow capacity $(\mathrm{L} / \mathrm{s})$, and $\Delta \mathrm{p}$ the overall differential pressure $(\mathrm{kPa})$. The estimated fan motor power draw for pneumatic transport is shown in Table 4.

Table 4. Fa. Motor Power Draw for Pneumatic Transport $(\mathrm{kW})$

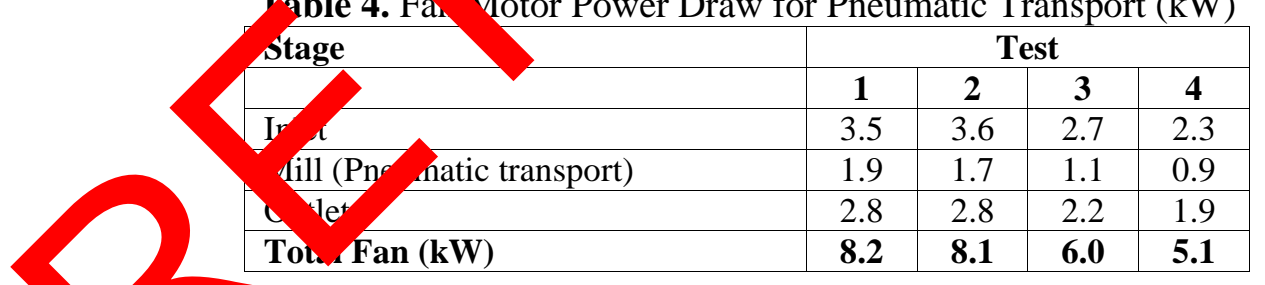

Th estimated value for the energy consum by the fan motor was used along with the direct logged mill motor (grinding table) power to calculate the overall specific energy consumption of the pilot-scale mill (see Table 5). The fan energy estimates were found to account for between 45 to $60 \%$ of the overall VRM energy consumption, broadly in agreement with the values reported in the literature. 
Table 5. Overall specific energy consumption and share of estimated fan energy

\begin{tabular}{|l|c|c|c|c|}
\hline \multicolumn{1}{|c|}{} & \multicolumn{4}{|c|}{ Test } \\
\hline Grinding table power, $\mathrm{kW}$ & $\mathbf{1}$ & $\mathbf{2}$ & $\mathbf{3}$ & $\mathbf{4}$ \\
\hline Fan power, $\mathrm{kW}$ & 5.6 & 6.6 & 6.2 & 6.3 \\
\hline Overall power, $\mathbf{k W}$ & 8.2 & 8.1 & 6.0 & 5.1 \\
\hline Grinding table specific energy, $\mathrm{kWh} / \mathrm{t}$ & $\mathbf{1 3 . 7}$ & $\mathbf{1 4 . 7}$ & $\mathbf{1 2 . 2}$ & $\mathbf{1 1 . 4}$ \\
\hline Fan specific energy consumption, $\mathrm{kWh} / \mathrm{t}$ & 9.5 & 7.8 & 10.3 & 10.6 \\
\hline Overall specific energy, kWh/t & $\mathbf{1 6 . 1}$ & 9.5 & 10.1 & 8.5 \\
\hline Fan specific energy as \% of overall & 59.4 & 55.0 & $\mathbf{2 0 . 4}$ & \multicolumn{1}{|c|}{} \\
\hline
\end{tabular}

The specific energy consumption estimates in Table 5 includes the energy consumption due to pressure losses at the mill inlet damper and the product filter. These specific energy estimates are related to material transport and classification operations in the mill and may not be as high in full scale operation as in pilot scale tests. This is especially true for overflow mode VRMs.

The differential pressure across a VRM is an indicator of the size of the circulating load that develops in the mill. Increased mill and air flow rates resul $\mathrm{c}$ inch sed mat ial recirculation and hen pressure lo a this effect is visible Figr 7a. Treased circulating loa ${ }^{\prime \prime}$ not ${ }^{\prime}$ ' results 'n reduced specific ene consum on gure 7b), but also hind or grindin of material (i.e. excessive fines) the mill (Figure 8) while pro similar qlues of $\mathrm{P}_{80}$. This is ar antageous since minimizing overgrinding is required most mineral comminution op ations.

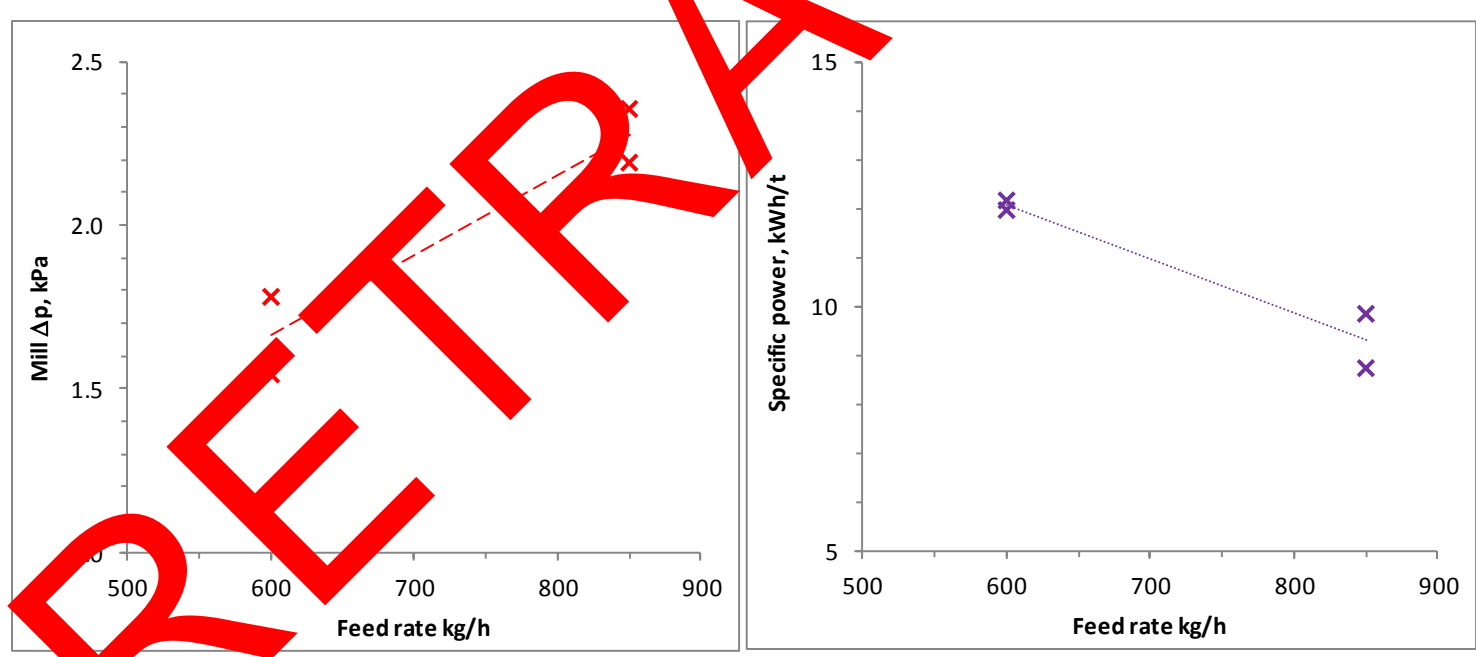

Figure 7. Effect of VRM feed rate on (a) mill pressure drop (circulating load) and (b) specific energy

The Bond equation [23] was used to estimate the specific energy consumption of a ball mill achieving a similar amount of size reduction to the VRM at similar throughputs as in the tests (see Table 6). 


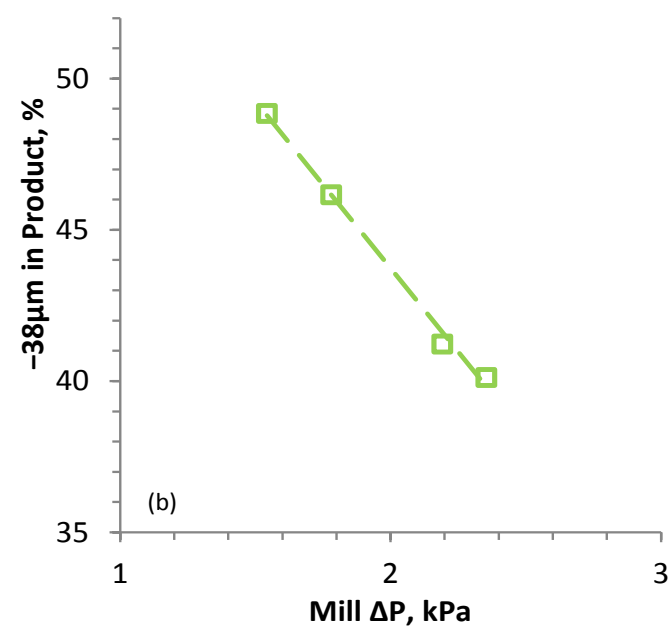

Figure 8. Effect of circulating load on product fineness
Comparing the VRM overall $\mathrm{kWh} / \mathrm{t}$ from Table 5 and adding $10 \%$ to the Bond $\mathrm{kWh} / \mathrm{t}$ from Table 6 to account for slurry pump power required for hydrocyclone classification, one may conclude that VRM and ball mill circuit are similar in energy consumption. However, at industrial scale, it is likely that VRM energy consumption by the fan motor will be less than $50 \%$ of the total and hence VRMs should provir better ergy efficiency. Moreover, it known hat overflow mode of operation rovides en better energy efficiene or these $1 \mathrm{lls}$ bo des the additional ady tages, g. no inding media and less we. no water requirement, smaller foot $\mathrm{p}$ it, etc.

Table 6. Estimated ball mill specific energy consumptions

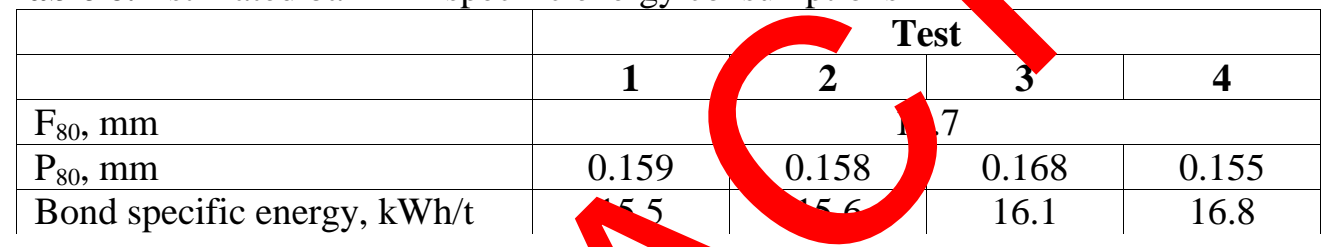

A comparison of the specific ener vern VRM, and a ball mill circuit is consumption for an air swep $\mathrm{M}$, an provided in Figure 9.

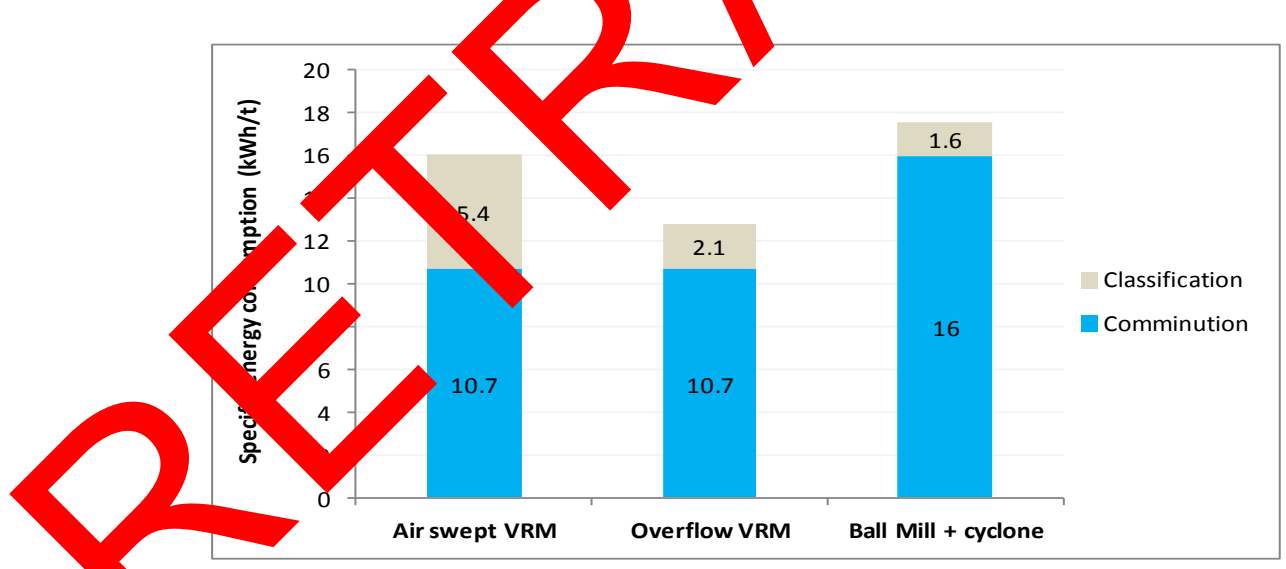

Figure 9. Comparison of estimated specific energy consumptions for VRM and ball mill circuits

This assumes that the specific energy required for material transport and classification is $20 \%$ for overflow VRM, $50 \%$ of comminution energy for air swept VRM (based on van Drunicket al. [14]) and 10\% for ball mill circuit closed with hydrocyclones. 
The VRM comminution specific energy is the average of the grinding table specific energies from Table 5 and the Bond specific energy data is from Table 6. This rather simplified analysis confirms the literature claims that VRMs with overflow design may be $30 \%$ more energy efficient than conventional wet ball mill circuits. There was insufficient data to investigate the effect of roller pressure. Studies in the literature indicate that the relative increase in power draw with pressure is often compensated for by changes in the amount of product $[24,25]$.

\section{Discussion}

Pilot scale testing determined that a HPGR in closed circuit with air classification generating final product $(\mathrm{P} 80$ of $50 \mu \mathrm{m})$ offered a power saving of about 20 to $30 \%$ compared to a HPGR in closed circuit with a $2.36 \mathrm{~mm}$ screen followed by ball milling. The specific energy consumption of the HPAR with air classification was $14.0 \mathrm{kWh} / \mathrm{t}$ ( $\mathrm{t}$ t direct power logging). For the HPGR closed circuit with a screen follo - by ba milling the specific energy con ampt $\mathrm{h}$ was $19.9 \mathrm{kWh} / \mathrm{tusing}$ direct por loggi nd $17.7 \mathrm{kWh} / \mathrm{t}$ when calcu ${ }^{1}$ ted viv Bond third law [16]. Further ond tests owed that the Bond work indic or andard jan rushed feed to $-3.35 \mathrm{~mm}$ and $-2.3 \mathrm{~m}$ were similar (15.0 and $15.3 \mathrm{Wh} / \mathrm{t}$, respect $\mathrm{ly}$ ), while the HPGR crus d feed $0-2.36 \mathrm{~mm}$ produced a lower Bond ork dex of $14.0 \mathrm{kWh} / \mathrm{t}$. These result aree hobse ations in literature tha $\widehat{P P G}_{\mathrm{PG}}$ rendo a ample more amenable comm on, most likely due to the int $y$, on of cro-cracks.

Th efore, the use of HPGR and air classific on for energy efficient grinding in the mining industry is promising. One concern is that the air classifier product contained an unexpectedly large proportion of coarse particles, which may be due to deficiencies of the actual laboratory unit or operating conditions. However, verification of this would require further investigation. Another consideration is that the final product size (P80 of $50 \mu \mathrm{m}$ ) used in this study is very fine (similar to that used in the cement industry), while the circulating load in the HPGR was $700 \%$, which is quite high. The circulating load in the HPGR would be expacted to be lower if the cut size of the ai classin was coarser, but ball milling mig be more en gy efficient at coarser grind s. s. It we ld therefore be of inter ot in fut wo to evaluate HPGR wi air cla fificatio gainst ball milling andscro vin or coarser product sizes with $\mathrm{P}^{\circ}$ in tho ange about 150$300 \mu \mathrm{m}$.

Meanwhile, vilot scale testing of conyentional (i.e. ir swept mode) VRM tre ang the same macrial to a product size v th a P80of bout $150-160 \mu \mathrm{m}$ resulted in o rall specifi energy consumption of 16.1 to 20. $\mathrm{kWh} / \mathrm{t}$ Comminution only specific nergy consumption during the tests was to be in the $8.7-12.2 \mathrm{kWh} / \mathrm{t}$ range. Industrial scale VRM is likely to have less energy consumption by the fan motor and overflow type VRM are known to provide even better energy efficiency.

For the material and size reduction in these tests, the specific energy consumption for industrial scale air swept VRM, overflow VRM and a ball mill circuit closed with hydrocyclones was estimated to be about 16 , 13 and $18 \mathrm{kWh} / \mathrm{t}$ respectively. Therefore, this preliminary comparison indicates that VRM, particularly with overflow design, is likely to be significantly more energy efficient than ball milling to achieve similar degree of comminution, justifying further investigation.

\section{Conclusion}

There is a growing interest in both HPGR and VRM for application to mineral ores due 
to the claimed benefits in energy efficiency as well as the fact that they are dry processes. These technologies have been successfully used in other industries for decades, but there are only a few examples in mineral ore applications to date. They can both potentially operate in similar roles, from final stages of crushing through to grinding applications, and can achieve a large reduction ratio in a single step.

Pilot scale testing was conducted for each of these technologies to test the claims in the literature and evaluate their suitability for hard rock mining operations. The VRM and HPGR pilot scale tests conducted in this study are not directly comparable (despite using the same test material) due to the different size reduction and final product size. However, both demonstrated the potential for considerable energy savings compared to conventional ball milling.

Furthermore, the benefits of these technologies appear not to be limited to improved energy consumption. technologies do not use grinding med (further reducing operating costs) $\rightarrow$ are $\mathrm{dr}$. processes. The HPGR crushed ampl had a lower Bond Work index th a jaw material; i.e. more an nab, furth comminution, and $Y M$ is orted to improve downstrea $\mathrm{p}$ cessing $\mathrm{o}_{\mathrm{l}}$ rations due to narrower size stributions and improved mir al liberation Given the potential en gy say gs and other benefits, further inve gati is warranted. HPGR and VRM exp sion and or be evaluated during sineerir dies.

\section{0. cknowledgements}

The HPGR pilot scale test work was conducted by Metso Process Technology and Innovation in collaboration with the CSIRO Minerals Down Under flagship. The authors thank CSIRO staff for their contribution. We are thankful to ALS Coal for the technical support during the VRM testing and contributions with their expertise.

\section{References}

[1] Van der Meer, F.P., Önol, S. and Strasser, S. (2012) Case Study of dry HPGR grinding and clase cation ore processing. In: 9th Int ational Mi ral Processing Confererce (k cemin 20 2), Gecamin, Santiag 32-34.

[2] Aydoğan, N.A Lrgün 7 and 1 Ler, H. (2006) Hinh res e gripding rolls (HPGR) applicat ns in the cement indus Minerals E. iv ering. 19, 130139

[3] wilden, M. nd Suthers, S.(2010) Comparing enery efficiency of multipass hig pressure grinding roll (HPGR) circuits. : XXV International Mineral rocessi of Congress (IMPC) 2010 Proucedings, The Australasian Institute f Mining and Metallurgy, Brisbane, 801-811.

[4] International Mining (2012) Better processing. International Mining. September 2012, 128.

[5] Weir Minerals, (2011) Introduction to High Pressure Grinding Roll Technology in Mining, Weir Minerals, Madison, USA.

[6] Brundiek, H. (1989) The roller grinding mill - its history and current situation part 1, Aufbereitungs-Technik, 30, 10, 609-619.

[7] Schaefer, H. V. (2001) Loesche vertical roller mills for the comminution of ores and minerals, Minerals Engineering, 14, 10, 1155-1160.

[8] Gerold, C., Schmitz, C., Stapelmann, M. and Dardemann, F. (2012) Recent installations and developments of Loesche vertical - roller - mills in the ore 
industry, Comminution '12, Cape Town, South Africa, 17 - 20 April 2012.

[9] Daniel, M.J. (2007) Energy efficient mineral liberation using HPGR technology. PhD Thesis, University of Queensland, Brisbane, Australia.

[10] Rosario, P and Hall, R, (2008) Analyses of the total required energy for comminution of hard ores in SAG mill and HPGR circuits. In: 5th International Mineral Processing Seminar (Procemin 2008), University of Chile, Santiago, 129-138.

[11] Feige, F.(1993) The roller grinding mill current technical position and potential for development, Zement-Kalk-Gips, 46, 10, E287-E292.

[12] Ito, M., Sato, K. and Naoi, Y. (1997) Productivity increase of the vertical roller mill for cement grinding, In: Cement Industry Technical Conference. XXXIX Conference Record. Hershey, PA, United States, 20 - 24 April 1997, 177-194.

[13] Altun, D., Gerold, C., Benzer, H., Af O., Aydogan, N. and Langel, J. (20 Ore grinding practices wit ${ }^{\text {t }}$ oesch OGP (ore grinding plant wobi 13th European Symposium Comp on \& Classification schwer Germany, 9 - 12 S tember 2 3, 63-66.

[14] vanDrunick, W it Id, C. and $I m, N$. (2010) Implementatio of an energy efficient $d$ grinding tec ology into an Anglo Amerion zinc beneficiation process In: 5th Mineral Processing C-rress Proce angs, Brisbane, Aust ia, 6 o ptember 2010, 1333 1341

[1. $C^{n}$ obie, $k$ Robertson, C., Smit, I. and V.(2005) The benefits of interpan e comminution on flotation, Centenary of Flotation Symposium, Brisbane, QLD, Australia, 6 - 9 June 2005, 823-828.
[16] Gupta, A. and Yan, D.S. (2006) Mineral Processing Design and Operation, Elsevier, Oxford.

[17] Jankovic, A., Suthers, S., Wills, T., Valery, W. (2015) Evaluation of Dry Grinding using HPGR in Closed Circuit with an Air Classifier, Minerals Engineering, 71, 133-138.

[18] Jankovic, A., Valery, W., Lee-D, Peres, J. and Jeston, S. (2013) alidath of a closed circuit ball mill odel, Journ of Mining and Met'llurgy Section A: Mining, 49, 1, 3743.

[19] Sherry, A., Be , J. S. Yruddà A. E., Fortune, H., Gle anning J. W., Hodgkin M, A. J., $\operatorname{artin}$.L., Murfit, R. H Myers, F. . (eds.) (1971) Moa.rn swer Sation Practice, Uungary: Pers non Press Ltd.

[2 Bernotat, S.(19) Classifiers in roller grinding hills, Zement-Kalk-Gips, 44, 2, 79-83 (EI lish translation: 4, 73-75).

[21) rugan M. (1992) State of the art raw gimming, Zement-Kalk-Gips, 45, 1, 9-13 English translation: 3, 59-62).

22] Karassik, I. J., Messina, J. P., Cooper, P. and Heald, C. C. (eds.) (2001) Pump Handbook, New York: McGraw-Hill.

[23] Bond, F.C.(1961) Crushing and grinding calculations part 1, Br. Chem. Eng. 6, 378-385.

[24] Little, W. M., Mainza, A. N., Becker, M., Gerold, C., Langel, J. and Naik, S. (2015) Assessing the performance of the vertical roller mill for grinding Platreef ore, SAG Conference 2015, Vancouver, Canada, 20 - 23 September 2015, Poster 19.

[25] Spero, C. (1989) The influence of coal properties on the grinding and wear characteristics of ring-and-ball pulverisers, Master of Engineering Thesis, Queensland University of Technology. 


\title{
OCENA HPGR I VRM ZA SUVO USITNJAVANJE MINERALNIH RUDA
}

\begin{abstract}
A. Jankovic ${ }^{1, \#, ~ C . ~}$ Ozer $^{2}$, W. Valery ${ }^{3}$, K. Duffy ${ }^{1}$
${ }^{1}$ Metso Process Technology and Innovation, PO Box 221, Kenmore, QLD 4069, Australia

${ }^{2}$ Metso Process Technology and Innovation, P.O. Box 306, FI-33101, Tampen - inland

${ }^{3}$ University of Queensland, St Lucia QLD 4072, Australia

(Primljen: 2. Februar 2016.; Prihvaćen: 4. Novembar, 20\%.)

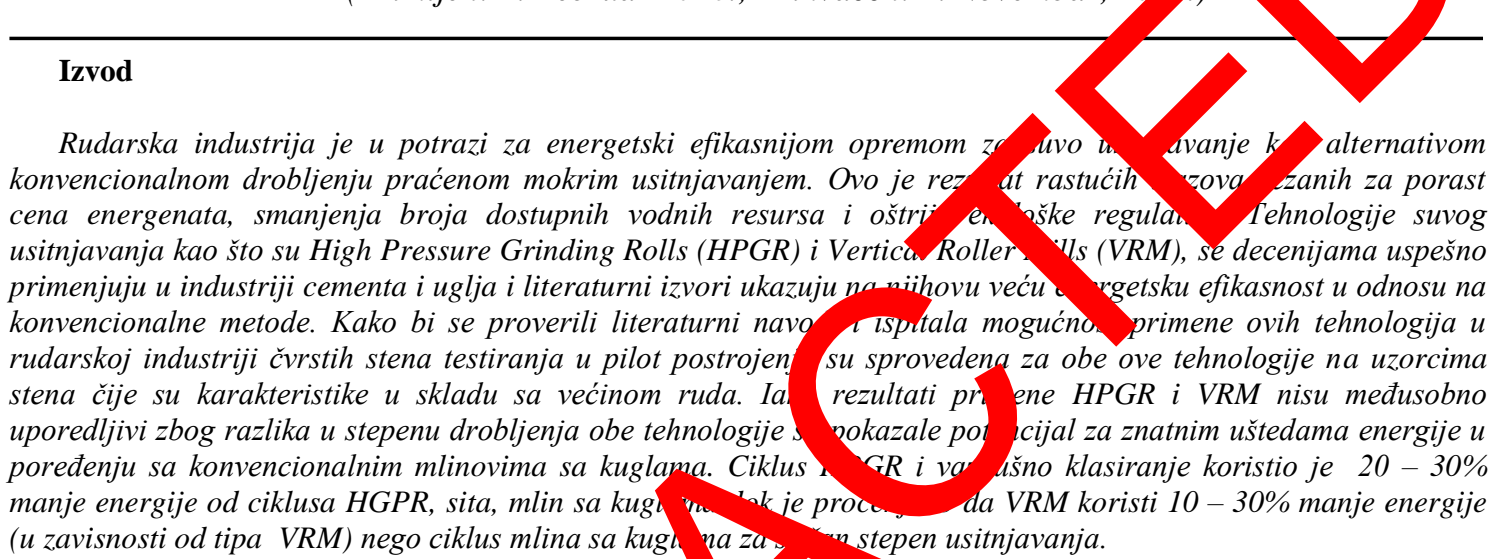

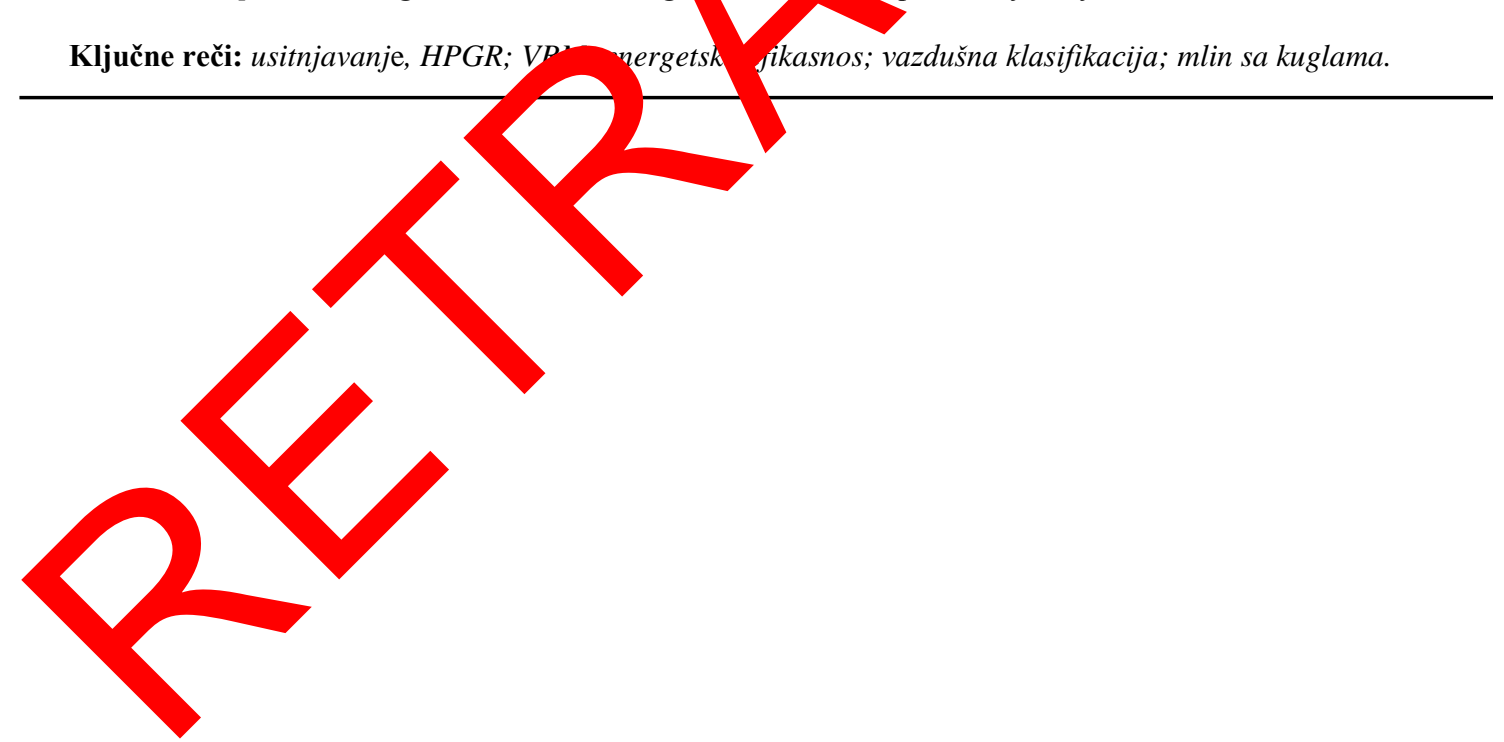

${ }^{\#}$ Kontakt adresa autora: alex.jankovic@metso.com 